SlavVaria 1/2021. 351-361

DOI: $10.15170 /$ SV.1/2021.351

ЮЛИАНА ЮРЬЕВНА ТЮРИНА

(Москва, Россия)

\title{
О некоторых приёмах работы над ритмикой и интонацией в преподавании РКИ
}

Аннотация: Акцентоцентричность русского фонетического слова важный аспект изучения РКИ и постановки правильного произношения. Словесное ударение представляет собой не только основу ритмической организации фонетического слова, но и неотъемлемую часть интонационного оформления высказывания. Статья содержит практические рекомендации, позволяющие упростить и ускорить процесс усвоения ритмических моделей и интонационных конструкций русского языка.

Ключевые слова: акцентоцентричность, ритмика, интонация, звучащая речь, преподавание РКИ

Говоря об овладении произношением при изучении иностранного языка, прежде всего имеют в виду освоение звуков. Особое внимание уделяется, как правило, так называемым «трудным» звукам: например, при изучении русского языка трудности у представителей многих языков могут вызывать твёрдый [л], различение [л/р], шипящие и свистящие, [б/в], [п/ф] и т.д. Недостаточная твёрдость и недостаточная мягкость согласных звуков, недостаточная звонкость и избыточная глухость, наличие или отсутствие аспирации, различие локации и артикуляции сходных звуков, например [t] и [т], - все эти моменты находятся в фокусе внимания преподавателя и учащихся в процессе овладения произношением.

Однако успешное овладение произношением звуков является необходимым, но ещё не достаточным условием для овладения произношением в целом.

\section{I. Ритмика}

Наряду с освоением произношения звуков необходимо уделять внимание обучению произношению слов и групп слов как изолированно, так и в потоке речи. Правильно произнесённые звуки не могут обеспечить успешную коммуникацию, если нарушена ритмическая структура фонетического слова. Фонетическое слово - это единица звучащей речи, характеризующаяся отнесённостью к одному ударному слогу. Фонетическое слово может быть равно одному слову или может включать в себя служебные части речи, относящиеся к этому слову: проклитики 
(предлоги, частица не) и энклитики (частицы ли, бы и др.). Ударение фонетического слова может падать на знаменательную часть речи, тогда предлоги или частицы остаются безударными; либо ударным может оказаться предлог или частица, тогда знаменательная часть речи остаётся безударной (Ср.: «Я не знаю, как там в Лондоне, я не была́» - «не́ было печали, просто уходило лето»; «На берегу́ пустынных волн стоял он, дум великих полн» - «Выходила на́ берег Катюша...».) И в том и в другом случае фонетическое слово произносится слитно.

Ритмическая структура фонетического слова - это определённым образом организованное расположение ударных и безударных слогов, из которых это слово состоит.

Русское слово можно охарактеризовать как акцентоцентричное, потому что его звучание зависит от местоположения ударного слога и степени удалённости от него безударных слогов, один и тот же корень или какаялибо иная морфема звучит по-разному в зависимости от расположения ударного слога. Сравним звучание корня «город» в разных позициях: город [го́рът], городско́й [гър/ц...], иногоро́дний [...г/ро́д...], за́городный [...гъръд...]; звучание приставки «по-» в разных позициях: по́нял [пó...], поня́тно [n/...], поняла́ [пъ...].

Оставляя в стороне ситуации, когда русский язык изучается со слуха (дети в смешанных семьях, мигранты, приезжающие в Россию на неквалифицированные виды работы), можно сказать, что изучение русского языка как иностранного в учебных заведениях основано на письменном тексте. Влияние графического образа слова всегда или почти всегда оказывается мощнее, чем влияние звукового образа слова - учащийся слышит произношение преподавателя, но сам произносит слово так, как оно пишется, а не так, как оно слышится. При первом знакомстве с какимлибо словом предпочтение неизменно отдаётся именно его графическому варианту и лишь позже, в результате многократного использования частотных слов их произношение корректируется и приближается к аутентичному. Менее частотные слова зачастую так и остаются недоработанными в этом отношении и произносятся полностью или частично в соответствии с их графическим образом («частично» - в данном случае означает, что, например, корень слова произносится в соответствии с написанием, а окончание, будучи привычной морфемой вследствие частого использования её в составе других слов, произносится с учётом правил редукции).

Для устранения ошибок произношения в области ритмики целесообразно познакомить учащихся с формулой, которую её создатель А.А. Потебня описывает следующим образом: «Несмотря на многие исключения, для всего Ювр (южно-великорусского наречия - Ю.Т.) имеет силу следующее правило: слог третий от ударяемого слабее второго, предшествующего ударяемому, и равен слогу, следующему за ударяемым. Если тоническую силу ударяемого слога обозначить через 3, то 
отношение других слогов к ударяемому в четырёхсложном слове можно будет изобразить так: $1,2,3,1$. По такой формуле построены слова: к'чато́чик, пиряре́жим. Чтоб легче было находить примеры, возьмём вместо приведённой формулы две, т.е. формулу 1, 2, 3 (трёхсложное слово с ударением на последнем: х’рашо (или хырашо), в тиряму́) и формулу 3, 1 (двухсложное сл. с ударением на 1-м слоге: я́'д (я́гыд), те́рим). Сходство между изменениями неударяемых твёрдых и мягких здесь полное. Глухой звук из о в первом и четвёртом слоге соответствует звуку $и$ из $e$ в тех же слогах; $a$ из $o=я$ из $e$ во вторых слогах. В словах четырёхсложных с основными $o$ или $e$ тон возрастает до третьего слога, а на четвёртом падает на ту степень, на которой был на первом слоге. Трёхсложных слов с ударением на первом слоге, таких, из которых можно бы видеть тоническое отношение последнего слога к предпоследнему, нашлось мало: выс'сыла, казле́н'чик. Из них видно, что на третьем за ударяемым сила такая же, как на втором, или малым чем больше, так что формула будет: 3, 1, 1. - Для таких слов, как пык'лати́л, которых тоже нашлось очень мало, формула: 1, 1, 2, 3.

Во всём этом видно, что в Юж.-Вр. (южно-великорусском - Ю.Т.) ударяемый слог имеет бо́льшее значение, резче выдвинут, чем в Свр. и Мр. (северо-великорусском и малорусском - Ю.Т.) и что слоги неударяемые в Юж.-Вр. тем самым более остаются в тени, чем в вышеупомянутых наречиях» (ПОТЕБНЯ 1866: 66-67).

Сегодня формула ...112311... , где цифра 3 обозначает ударный слог, цифра 2 первый предударный, а цифра 1 все остальные предударные и заударные слоги, называется формулой Потебни и широко используется в преподавании РКИ. Практика показывает, что сложностей в понимании этой формулы учащимися, как правило, не возникает. Кроме того, есть и другие варианты подачи этой формулы (если цифровой вариант по какимлибо соображениям неприемлем). Например, можно нарисовать над слогами какие-либо значки, например, звёздочку, квадратик, кружок, таким образом, чтобы над ударным слогом располагался самый большой по размеру значок, над первым предударным - средний, над всеми прочими слогами - наименьшие по размеру значки. Можно представить ритмическую структуру русского слова в виде волны: спокойная низкая вода - это 1, волна растёт, поднимается - это 2, затем она с силой обрушивается вниз - это 3, и опять спокойная гладь воды - 1. Сочетание нескольких способов подачи этого материала на уроке также даёт обычно хороший результат. Одним словом, любое образное представление, близкое самому преподавателю, поможет учащимся осознать главное: «Ударение современного русского языка количественно-динамическое: гласный ударного слога, в отличие от безударных гласных, характеризуется относительно бо́льшей напряжённостью произнесения, большей длительностью, а потому и более чётким звучанием» (РУССКАЯ ГРАММАТИКА 1980: 90). Ударный слог звучит более отчетливо, ясно, 
«аккуратно», а гласный звук ударного слога произносится в соответствии со своим графическим изображением, «звук соответствует букве».

Первый предударный слог является местом наращивания, накопления энергии, которая затем будет выпущена на ударном слоге. Все остальные слоги характеризуются ненапряжённостью, краткостью, нечёткостью, «остаются в тени», по выражению А.А. Потебни.

Формула Потебни характеризует произношение фонетического слова, то есть распространяется на предлоги и частицы: «маши́на»- 231 ; «на маши́не»-1231.

Познакомив учащихся с формулой Потебни в том или ином виде, преподаватель переходит к тренировке правильного применения этой формулы на практике. Для этого учащимся предлагаются различные двух-, трёх-, четырехсложные ритмические модели типа: та́-та, ma-má, má-ma-ma, ma-má-ma, ma-ma-má и т.д., а также слова, соответствующие этим моделям. «Овладение ритмической структурой русского слова осуществляется путём многократного проговаривания ритмических моделей разного звукового наполнения. Выделяется девять типов (по другим данным - 16, из них активных 12 - Ю.Т.) ритмического оформления слов в русском языке, представляющих собой ритмическую базу для обучения нерусских:
1. тата́ - '-: страна́, вода́, родно́й, ходи́ть, тепло́;
2. та́та - - : кнйга, вре́мя, но́вый, де́лать, на́до, пло́хо;
3. татата́ - - '-: институ́m, голубой, погуля́ть, хорошо́;
4. та́тата - - -: де́вушка, ро́зовый, высскочил, хо́лодно;
5. тата́та - - -: рабо́та, прия́тный, заме́тил, случа́йно;
6. тата́тата - - --: заня́тия, кори́чневый, понра́вился, по-но́вому;
7. татата́та - - -: переда́ча, арома́тный, оказа́лся, некраси́во;
8. тататата́ - - - переворо́т, передава́ть, нехорошо́;
9. та́татата - - - -: ма́ленького, сла́бенького» (ЛЕБЕДЕВА 1986: 24-25).

Основным моментом контроля при этом является степень открытости рта, то есть расстояние между верхними и нижними зубами. Важно воспитать у учащихся привычку «закрывать рот», то есть максимально уменьшать створ рта сразу после ударения. Эта привычка значительно улучшает произношение с точки зрения ритмики, приближая его к аутентичному. Следует продемонстрировать различие между правильным произношением, когда напряжённость резко уменьшается на заударной части слова, и неправильным, когда напряжённость сохраняется на всех слогах. Обычно учащиеся с интересом реагируют на такую сравнительную демонстрацию и лучше усваивают эту особенность русского произношения. В дальнейшем преподаватель следит за тем, чтобы эта привычка приобретала стабильность. Кроме того, следует уделять внимание и предударной части слова. Очень распространённой является ошибка, заключающаяся в том, что приставки по-, про-, на- и др. 
произносятся одинаково в позициях 1 и 2. Вообще, в предударной части слова нужно следить за тем, чтобы слог в позиции 1 произносился закрыто, в противном случае слог в позиции 2 потребует слишком сильного открывания рта, что вызовет неудобство и неестественность звучания. Необходимо найти соответствующий баланс - определить, насколько можно открыть рот в позиции 1, чтобы «хватило сил» на позицию 2. Все эти тонкости обсуждаются и демонстрируются преподавателем в начале работы над ритмикой, а в дальнейшем, как правило, учащиеся легко корректируют своё произношение либо самостоятельно, либо получив принятый в данной учебной группе сигнал преподавателя об этой ошибке. Таким сигналом может служить, например, напоминание о формуле Потебни: «молоко́»,- 123 , либо называние ритмической модели: «молоко́» - та-та-та́, либо прямая инструкция о необходимых действиях: «молоко́» - «закрыли-открылиудар» и т.п.

Есть основания думать, что и сама редукция гласных в безударных слогах является, в каком-то смысле, результатом укоренившейся привычки прикрывать рот, ослабляя при этом мышечное напряжение органов речи.

\section{Следует сделать несколько замечаний:}

1. Соблюдение баланса открытости-прикрытости рта важно не только тогда, когда речь идёт о редукции О и А после твёрдых согласных, но и при редукции Е и Я после мягких согласных. Вообще, прикрытость рта и ослабление мускульной напряжённости органов речи в безударных слогах - необходимое условие естественного звучания редуцированных гласных. Попытки учащихся воспроизвести редуцированный гласный без соблюдения этого условия (например, произносят [хырашо́] вместо [хър/щшó]) приводят к неестественности звучания, воспринимаемого как ошибочное.

Следует также обращать внимание учащихся на то, что ослабление напряжённости и прикрывание рта в позиции 1 (по Потебне) сопровождается и сокращением длительности гласного звука в этих безударных слогах. Например, венгерский акцент в русском языке характеризуется практически одинаковой напряженностью и длительностью гласных во всех слогах, как в ударных, так и в безударных; в то время как в речи носителей русского языка длительность гласных в ударных и безударных слогах соотносится в пропорции 2(1,5) : 1. Это объясняется серьёзными различиями в области ритмики между русским и венгерским языками: «Известно, что в венгерском языке не бывает словесного ударения на чётных слогах, кроме того, различаются главное и дополнительное ударения в словах (главное падает на первый слог, а на других нечётных слогах бывают ещё дополнительные ударения). Иначе 
говоря, в венгерском языке нечётные слоги более интенсивны по сравнению с чётными, а на пятом слоге ударение сильнее, чем на третьем. Из практики известно, с каким трудом осваивают венгерские учащиеся ритмику русского слова и место словесного ударения» (ЛЕБЕДЕВА 1986: 27).

В процессе объяснения и тренировки произношения слогов с разными по длительности гласными используется такой приём, как проговаривание слов, сопровождаемое хлопками, так чтобы короткому гласному соответствовал один хлопок, а длинному - два.

2. В речи носителей языка в первом предударном слоге (позиция 2 в формуле Потебни) фонема Е может реализоваться как [иㅜㄹ: вчера́ [фч'u'pá], сего́дня [c’uвódн'b]. Однако в практических целях целесообразно указывать в этой позиции просто [и], поскольку неверно сбалансированный оттенок [э] приводит к ошибке произношения ([фч'эра́], [c’эво́дн’ь]), тогда как [и] без оттенков в указанной позиции никогда не воспринимается носителями языка как ошибочный.

3. Согласно правилам редукции, в заударных слогах И, Е и Я реализуются как [ь] - слабый короткий «и». Однако в том случае, когда мы имеем дело с окончаниями существительных или глаголов, грамматика превалирует над фонетикой. В речи носителей языка по́ле и По́ля, те́рпит и т́ерпят звучат по-разному и почти всегда различаются на слух. Не исключено, безусловно, что на восприятие подобных словоформ влияет контекст, однако и в изолированном звучании носители языка, как правило, различают флексии падежей и чисел. В связи с этим возникает необходимость корректировки транскрипции флексий, а также корректировки рекомендаций по произношению этих флексий, которые преподаватель даёт учащимся. Так, например, безударные флексии,

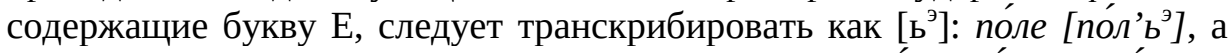

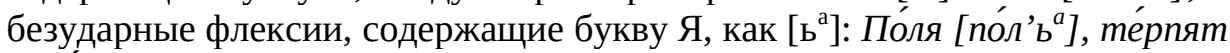
$\left[m^{\prime}{ }^{\prime} n^{\prime}{ }^{a} m\right]$. При этом практическая рекомендация предлагается следующая: в безударных окончаниях нужно читать то, что написано, но при этом максимально прикрывать рот. Эта простая рекомендация обычно легко понимается учащимися и быстро приводит к желаемому результату.

4. При обучении русскому языку учащихся-нефилологов представляется не столь обязательным транскрибировать слова по всем правилам. Главной целью является обеспечение понимания учащимися рекомендаций преподавателя, поэтому нужно представлять материал такими способами, которые быстрее и эффективнее приведут к достижению этой цели. Например, правильное произношение безударных флексий с буквами Е, Я, о которых говорилось в п. 3, зависит от степени 
открытости рта. Продемонстрировать это можно, используя в написании соответствующих слов прописные и строчные буквы: ПО́Ле, ТЕ́РПят. Такой способ записи легко воспринимается учащимися и приводит к быстрому результату.

5. Важной характеристикой русского фонетического слова является слитность произношения. Игнорирование этой особенности ведёт к тому, что представители некоторых языков, например, японского и др., демонстрируют «рубленную», отрывистую речь, когда гласные звуки произносятся в отрыве от следующих за ними согласных. В результате этого возникают микропаузы между слогами внутри слова, с одной стороны, и вкрапления огласовок между согласными, с другой стороны: са́кура [cá//ку//pa], вчера́ [фу//ч’u//pá]. Следует продемонстрировать учащимся, что в русском языке гласный в составе слова заканчивает своё звучание только тогда, когда начинает звучать следующий за ним звук, согласный или гласный: не сa//, а сак, не ку//, а кур в слове «сакура». Для достижения плавности и слитности произношения можно использовать следующий приём - разбить фонетическое слово на открытые слоги, например: под столом [па-цтта-ло́м] (последний слог не всегда получается открытым), ќошка [ко́-шка], затем произносить слова так, чтобы гласные звуки прекращались не раньше, чем начнутся следующие за ними согласные. Что касается групп согласных в начале слога, то их следует произносить как одно целое, концентрируя внимание на последнем из них. В приведённых примерах в слоге -цта- внимание сосредоточено на согласном $m$, а не на $u$, в слоге -шка- внимание на согласном $k$, а не на $u$. Как показывает практика, этот способ тренировки слитности произношения достаточно эффективен. (Разъясняя, при необходимости, описанный приём более подробно, можно сказать, что в производстве согласного звука выделяются две части - экскурсия и рекурсия (для удобства в данном случае игнорируется промежуточная часть - выдержка). Экскурсия - это движение органов речи в положение, необходимое для производства согласного звука («идём на звук»), а рекурсия - это обратное движение, уход с позиции («уходим от звука»). В группе согласных рекурсия в полном объёме выполняются лишь для последнего из них, а для остальных рекурсия совпадает с экскурсией следующего согласного. Этим достигается слитность произношения групп согласных).

\section{II. Интонация}

В процессе обучения РКИ работа над произношением ведётся на всех уровнях: звук - слог - слово - словосочетание - предложение - текст. На уровне предложения и текста важную роль играет интонация, под которой понимается «звуковое средство языка, с помощью которого говорящий и слушающий выделяют в потоке речи высказывание и его смысловые части, противопоставляют высказывания по их цели 
(повествование, волеизъявление, вопрос) и передают субъективное отношение к высказываемому» (РУССКАЯ ГРАММАТИКА 1982: 96).

Всё многообразие изменений основного тона звучащего предложения сводится к семи типам интонационных конструкций (ИК), в составе каждой из которых выделяются центр, предцентровая и постцентровая части. «У каждого говорящего есть свой средний тон, на котором обычно произносятся предцентровые части ИК. Повышения и понижения тона, которые происходят в центре ИК, становятся значимыми при сравнении со средним тоном.

Средний тон говорящего характеризуется определённым диапазоном, в пределах которого возможны незначительные повышения и понижения. Эти колебания тона - одно из важнейших средств выражения эмоционального состояния говорящего и в то же время второстепенны для таких различий, как, например, вопрос-сообщение. Поэтому на схемах средний тон обозначен ровной линией, его колебания обычно не передаются» (БРЫЗГУНОВА 1977: 17).

В связи с этим (т.е. обозначением предцентровой части ровной линией) в ходе освоения ИК у учащихся возникают затруднения. Попытки точно следовать схеме приводят к тому, что предцентровая часть звучит неестественно, монотонно, ударные слоги не выделяются, дыхание задерживается, иногда, если предцентровая часть достаточно длинная, учащемуся не хватает воздуха, чтобы закончить предложение, а также наблюдаются затруднения при изменении тона в центре ИК. Кроме того, замечено, что смысл произнесённой таким образом фразы ускользает не только от слушающего, но и от самого говорящего, создаётся впечатление, что говорящий не понимает того, что он говорит. Исправить эти недостатки можно следующим образом:

1. Ударные слоги слов предцентровой части должны стать точками опоры для говорящего. Интонационный рисунок фразы не подменяет собой ритмический рисунок слов, а включает его в себя. На ударных слогах предцентровой части тон слегка повышается по типу ИК-6, на остальных слогах тон остаётся на обычном среднем уровне. Повышение тона происходит больше за счёт усиления энергии, напряжённости ударных слогов, а не за счёт мелодики, но воспринимается именно как повышение музыкального тона. Важно избегать слишком сильного повышения и продемонстрировать учащимся разницу между действительным повышением мелодического тона по образцу ИК-3 или ИК-6 и повышением за счёт усиления энергетики ударного слога. При таком сравнении разница становится очевидной. Для наглядности объяснение можно дополнить рисунком, корректирующим обычную схему предцентровой части. Вот как может выглядеть такой рисунок для предложения «Многие европейцы посвятили жизнь русской культуре» (АРХАНГЕЛЬСКИЙ 2020: 9) 


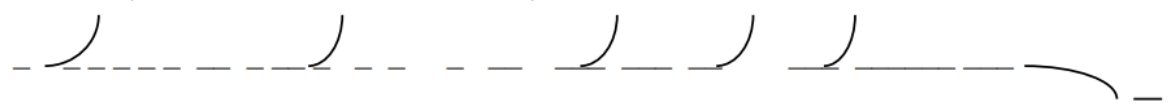

МНО́-ГИ-Е Е-ВРО-ПЕ́-ЙЦЫ ПО-СВЯ-ТИ́-ЛИ ЖИЗНЬ РУ́-ССКОЙ КУ-ЛЬТУ́-РЕ

Графическое представление предцентровой части ИК-1 в данном примере показывает небольшие подъёмы тона над ударными слогами при сохранении общего среднего тона, понижение тона на ударном гласном главного слова («культуре») и низкий уровень тона на постцентровой части.

Как и в других разделах фонетики, в области интонации необходимо формировать и развивать навыки самоконтроля, умение учащихся различать высоту тона в речи носителей русского языка, слышать себя и в достаточной мере владеть голосом, чтобы корректировать работу голосовых связок. Многократное повторение предложений с изучаемым типом ИК, сопровождаемое графическим изображением, жестами, сочетание скрупулёзного, послогового анализа ИК с имитацией её мелодического звучания как единого целого (Задание учащимся: «Слушайте мелодию фразы, повторяйте») - всё это формирует навыки самоконтроля, который, в свою очередь, позволит добиться автоматически правильного интонирования.

2. Существует ещё один приём, помогающий учащимся осваивать русскую интонацию. В разделе «Интонация» Русской грамматики АН СССР 1982 года Е.А. Брызгунова пишет: «Уровень тона предцентровой части ИК является линией отсчёта для повышения и понижения тона на гласном центра. Разные типы ИК характеризуются сосредоточенностью колебаний тона в средне-верхней или средне-нижней полосе диапазона предцентровой части. В эмоциональной речи колебания тона более разнообразны по сравнению с речью нейтральной» (РУССКАЯ ГРАММАТИКА. 1982: 102). Предцентровые части различных ИК в «Русской грамматике» характеризуются следующим образом:

1) В предцентровой части ИК-1 колебания тона имеют восходященисходящее направление или сосредоточены в средней полосе её диапазона. Гласный центра произносится с нисходящим движением тона ниже уровня предцентровой части. (...);

2) ИК-2. В предцентровой части колебания тона сосредоточены в средне-верхней полосе её диапазона. Гласный центра произносится с нисходящим или ровным движением тона в диапазоне предцентровой части или ниже её, если центр находится в конце конструкции (...); 
3) В предцентровой части ИК-3 колебания тона сосредоточены в средней полосе её диапазона. Гласный центра произносится с восходящим движением тона выше уровня предцентровой части (...);

4) В предцентровой части ИК-4 колебания тона сосредоточены в средне-верхней полосе её диапазона или образуют восходященисходящее направление. Гласный центра произносится на уровне тона ниже предцентровой части; при этом варьируется ровное, нисходящее, нисходяще-восходящее, восходящее направление тона (...);

5) ИК-5. В предцентровой части колебания тона сосредоточены в средне-нижней полосе её диапазона. Гласный первого центра произносится с восходящим движением тона выше уровня предцентровой части (...);

6) В предцентровой части ИК-6 колебания тона сосредоточены в средней полосе её диапазона. Гласный центра произносится с восходящим движением тона выше уровня предцентровой части (...);

7) В предцентровой части ИК-7 колебания тона сосредоточены в средней полосе её диапазона. Гласный центра произносится с восходящим движением тона выше уровня предцентровой части (...). (РУССКАЯ ГРАММАТИКА. 1982: 109-118)

Таким образом, в тех ИК, где гласный центра произносится с восходящим движением тона (ИК-3, 5, 6, 7), колебания тона в предцентровой части сосредоточены в средней и средне-нижней части диапазона. В то время как в тех ИК, где гласный центра произносится с нисходящим (либо нисходяще-восходящим) движением тона (ИК-1, 2, 4) колебания тона в предцентровой части сосредоточены в средней и средне-верхней части диапазона. Практика обучения навыкам произношения различных типов ИК показывает, что учащиеся испытывают затруднения, пытаясь произнести предцентровую часть ИК строго на среднем уровне тона и затем осуществить восходящее или нисходящее движение тона на гласном центра. Однако этот процесс заметно упрощается, если использовать допустимые отклонения в сторону повышения или понижения в рамках средней полосы диапазона ИК. При этом, следуя обозначенной тенденции, следует произносить предцентровую часть на средне-нижнем уровне средней полосы перед восходящим движением на гласном центра и на средне-высоком уровне средней полосы диапазона перед нисходящим движением на гласном центра. Сокращая и упрощая, можно сформулировать данную рекомендацию для учащихся следующим образом: если интонация пойдёт вверх, начинать нужно ниже (ИК-3, 5, 6, 7); если интонация пойдёт вниз, начинать нужно выше (ИК-1, 2, 4). Такой своеобразный «разгон» на предцентровой части придаёт естественность звучанию ИК и облегчает процесс их усвоения. 
Все эти приёмы постановки и коррекции правильного произношения в области ритмики русского фонетического слова и интонации многократно апробированы в рамках семинарских занятий по фонетике русского языка для учащихся уровня А2 и выше в Институте русского языка и культуры МГУ имени М.В. Ломоносова, а также в ходе индивидуальных занятий с изучающими русский язык стажёрами МИД Японии в Москве.

\section{Литература}

АРХАНГЕЛЬСКИЙ А.Н. (2020) Русофил. Москва, 2020.

БРЫЗГУНОВА Е.А. (1977) Звуки и интонация русской речи. Москва, 1977.

ЛЕБЕДЕВА Ю.Г. (1986) Звуки, ударение, интонация (учебное пособие по фонетике русского языка для иностранцев). Москва, 1986.

ПОТЕБНЯ А.А. (1866) Два исследования о звуках русского языка: I - О полногласии, II - О звуковых особенностях русских наречий. Воронеж, 1866. РУССКАЯ ГРАММАТИКА (1982) Москва: АН СССР, 1982.

About some techniques of working on rhythm and intonation in teaching Russian as a foreign language (RFL). Accent-centricity of the Russian phonetic word is an important aspect of the study of RFL and the correct pronunciation. Verbal stress is not only the basis of the rhythmic organization of a phonetic word, but also an integral part of the intonation of the utterance. The article contains practical recommendations that simplify and speed up the process of mastering rhythmic patterns and intonation structures of the Russian language.

Keywords: accent-centricity, rhythm, intonation, sounding speech, teaching of RFL 